\title{
CrimRxiv
}

\section{A Meta-Analysis of the Effects of Wilderness Therapy on Delinquent Behaviors Among Youth}

Natalie Beck, Jennifer S. Wong

Published on: Mar 04, 2022

DOI: $10.21428 / \mathrm{cb} 6 a b 371 . e 81872 f 8$

License: Creative Commons Attribution 4.0 International License (CC-BY 4.0). 
